\title{
TAGARELA: Módulo de composição musical para musicoterapia
}

\author{
Roberto Weege Junior ${ }^{1}$, Dalton Solano dos Reis ${ }^{1}$, Mauricio Capobianco Lopes ${ }^{2}$ \\ ${ }^{1}$ Departamento de Sistemas e Computação \\ Universidade Regional de Blumenau (FURB) - Rua Antonio da Veiga, 140 - CEP 89.030-903 - \\ Blumenau, SC - Brasil \\ ${ }^{2}$ Programa de Pós-Graduação em Ensino de Ciências Naturais e Matemática \\ Universidade Regional de Blumenau (FURB) - Blumenau, SC - Brasil \\ robertoweegejr@gmail.com, dalton@furb.br, mclopes@furb.br
}

\begin{abstract}
This article presents an application that aims to assist music therapists in the application of musical composition activities during therapy sessions. The musical composition activity provided by the application consists in enabling the user, who is in therapeutic activity, to choose musical fragments and edit their sound properties. The development method followed the premises of Software Engineering. To check the performance of the application, a test was conducted in a music class with an autistic student and an interview with two professionals. The application achieved its objective, since, during the test, the student managed to use the application and remained entertained with the composition process, in addition to being well evaluated by the professionals.
\end{abstract}

Resumo: Este artigo apresenta um aplicativo que tem como objetivo auxiliar musicoterapeutas na aplicação de atividades de composição musical durante sessões de terapia. A atividade de composição musical proporcionada pelo aplicativo consiste em possibilitar que o usuário, que está em atividade terapêutica, escolha fragmentos musicais e edite suas propriedades sonoras. O método de desenvolvimento seguiu as premissas da Engenharia de Software. Para verificar o desempenho do aplicativo, foi realizado um teste em uma aula de música com um aluno autista e entrevista com dois profissionais. $O$ aplicativo alcançou seu objetivo, uma vez que, durante o teste, o aluno conseguiu realizar a utilização do aplicativo e se manteve entretido com o processo de composição, além de ter sido bem avaliado pelos profissionais.

\section{INTRODUÇÃO}

A música é um elemento que estimula o ser humano. Segundo Queiroz (2000, p. 15), “a música tem como qualidade intrínseca relaxar a sensoriedade humana, por satisfazê-la, e com isso conduz as pessoas a um estado receptivo e sensível, em especial quanto às emoções". Tomando proveito desses efeitos, a musicoterapia é um processo, segundo Bruscia (2016, p. 55), em que o musicoterapeuta utiliza diversas facetas da experiência musical, além das relações interpessoais geradas durante a terapia, para otimizar a saúde do paciente. Atualmente a musicoterapia é utilizada em diversos espaços, como escolas, clínicas, casas de repouso e asilos (Bruscia, 2016, p. 36). É uma prática utilizada para dar assistência a pessoas com distúrbios emocionais, transtornos psiquiátricos, necessidades especiais, dificuldades especiais, dependências químicas, estresse, pós-trauma, entre outros (Bruscia, 2016, p. 36). Nestas aplicações, diversos elementos musicais podem ser utilizados. Bruscia (2016, p. 59) destaca quatro métodos primários utilizados na musicoterapia: escutar, improvisar, recriar e compor. Estas são atividades em que o musicoterapeuta precisa envolver o paciente, sem necessariamente ensinar a ele teoria musical. Esta situação traz desafios que podem ser enfrentados mais facilmente com o auxílio da tecnologia. 
A utilização de softwares ajuda os terapeutas a obterem melhores resultados com seus pacientes. De acordo com Watanabe, Tsukimoto D. e Tsukimoto G. (2003, p. 20) quando foi utilizado um computador em atividade terapêutica se verificou "[...] melhora funcional em todos os pacientes, com aumento da destreza e agilidade no uso dos programas e dispositivos". Watanabe, Tsukimoto D. e Tsukimoto G. (2003, p. 20) também destacam que houve um aumento na motivação dos pacientes com a utilização do computador como ferramenta auxiliar de terapia. Um exemplo de software que pode ser aplicado em atividades terapêuticas é o Tagarela, que é uma plataforma que vem sendo desenvolvida em trabalhos de conclusão de curso da área de Cmputação da Universidade Regional de Blumenau. O Tagarela foi criado inicialmente como uma plataforma de comunicação alternativa, para auxiliar na melhora da capacidade de comunicação do paciente (Fabeni, 2012). Outros módulos começaram a ser adicionados ao Tagarela em outros trabalhos, como um módulo de jogo educacional (Ferreira, 2016), um módulo de ensino de Braille (Cazagranda, 2016) e um módulo destinado ao auxílio de crianças autistas na aquisição e desenvolvimento de linguagem (Sautner, 2017).

Considerando o exposto, este trabalho apresenta o módulo do Tagarela voltado à musicoterapia. Este módulo, em forma de aplicativo para dispositivos móveis, deve auxiliar o musicoterapeuta a aplicar atividades de composição musical. Estas atividades deverão proporcionar ao paciente a possibilidade de manipulação de elementos musicais sem a necessidade de conhecimento teórico musical, aumentando o interesse e a motivação do paciente, além de disponibilizar aos musicoterapeutas uma ferramenta que os auxilie em atividades terapêuticas personalizadas de composição musical e permitir que usuários realizem atividades de composição musical mesmo que não possuam conhecimentos de teoria musical.

Destaca-se que ao se consultar os trabalhos anteriores do evento sobre o tema utilizando-se a palavra musicoterapia, nenhum trabalho foi retornado. Ao se utilizar apenas a palavra música, seis trabalhos foram alcançados, conforme a Tabela 1. Utilizando-se a palavra partitura, obteve-se o trabalho de Bordini et al. (2016) que já havia sido recuperado na consulta anterior.

\begin{tabular}{|l|l|l|}
\hline Edição & Autores & Aplicação \\
\hline 2012 & Moura, Edson. & Experiência com músicas e tecnologias na Educação Básica. \\
\hline 2013 & Pinhati, Fernando, Siqueira, Sean W. M. & Objetos de Aprendizagem para o ensino de música. \\
\hline 2014 & Miletto, Evandro M. et al. & AVA para criação coletiva de músicas. \\
\hline 2016 & Barbosa, Jaiane; Dourado, Tereza & Experiência com músicas e tecnologias na Educação Básica. \\
\hline 2016 & Vera, William F. M. et al. & Uso de músicas para o ensino de Computação. \\
\hline 2016 & Bordini, Rogério A. et al. & Jogo para o ensino de teclado e de leitura de partituras. \\
\hline
\end{tabular}
Fonte: elaborado pelos autores.

Tabela 1- Trabalhos de edições anteriores do CBIE

Nesse sentido, nenhum trabalho foi encontrado com as mesmas características do proposto neste artigo. O único que trabalha com partituras é o de Bordini et al. (2016), mas sem a possibilidade da construção de uma composição musical por parte do participante do jogo.

\section{FUNDAMENTAÇÃO TEÓRICA}

Barcellos (2004, p. 3) afirma que “[...] a educação musical pode contribuir para o desenvolvimento de cérebros normais, enquanto a musicoterapia é fundamental para minimizar os danos que afetam o cérebro, como resultado de tantas patologias". A musicoterapia é definida por Bruscia (2016, p. 55) como "[...] um processo reflexivo no qual o terapeuta ajuda o cliente a otimizar sua saúde, usando variadas facetas da experiência musical e as relações formadas através desta como o ímpeto para a transformação". Durante a musicoterapia, segundo Bruscia (2016, p. 125), as atividades que podem ser executadas estão relacionadas com ações de improviso, execução, composição e audição musical. 
Nas atividades de composição musical em musicoterapia, Bruscia (2016, p. 130) afirma que "o terapeuta ajuda o cliente a escrever canções, letras ou peças instrumentais, ou a criar qualquer tipo de produto musical, tais como clipes de música ou fitas de áudio". Algumas metas deste tipo de atividade são: desenvolver habilidades para expressar e organizar pensamentos e sentimentos, desenvolver habilidades de tomada de decisão e desenvolver habilidades de documentação e comunicação de sua composição para permitir que outros à reproduzam (BRUSCIA, 2016, p. 130).

A musicoterapia é baseada no som. Med (1996, p. 11) define que as principais características do som são a duração, a intensidade, a altura e o timbre. Segundo Lacerda (1967), a propriedade sonora de duração é determinada pelo tempo. Ambos os autores associam a duração do som com os elementos de notação musical: figura de nota, fórmula de compasso e andamento. A figura de nota, ou figura de som, é a forma gráfica da nota (Priolli, 2006). Priolli (2006, p. 13) afirma que "para representar as várias durações dos sons musicais as notas são escritas sob formas diferentes". Cada figura de nota possui uma figura de pausa respectiva, que representa a duração do silêncio e que possui a mesma duração da figura de nota correspondente (Priolli, 2006). A Figura 1 demonstra o nome e as formas das figuras de notas e das suas respectivas figuras de pausas. A fórmula de compasso é representada por dois números, um indicando quantos tempos existem em cada compasso e outro indicando a unidade de tempo (Lacerda, 1967, p. 20). O andamento é a velocidade de execução da música, o qual pode ser determinado com precisão utilizando-se de valores em batidas por minuto (bpm) (Lacerda, 1967).

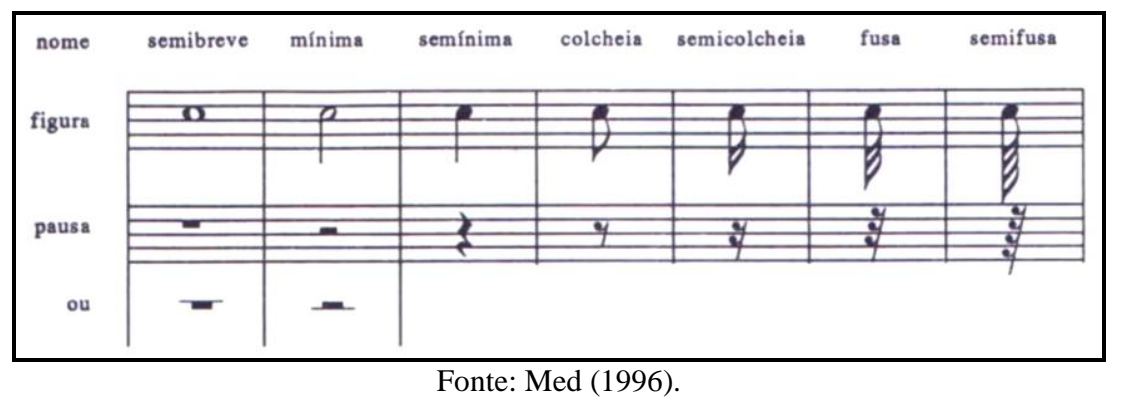

Figura 1 - Figuras de notas e figuras de pausas

A intensidade é determinada pela capacidade do som ser mais forte ou mais fraco (Lacerda, 1967). Med (1996) a caracteriza como a amplitude da vibração que gera o som e complementa relacionando a propriedade ao volume sonoro. Ambos os autores associam a propriedade de intensidade do som com o elemento sinais de dinâmica. Em ordem crescente de intensidade sonora os sinais de dinâmica apresentados são: ppp, pp, p, mp, mf, f, ff e fff. Nesta escala, o p significa intensidade sonora fraca e of significa intensidade sonora forte (Lacerda, 1967, p. 49).

A altura é determinada pela capacidade do som ser mais grave ou mais agudo (Lacerda, 1967). Med (1996) caracteriza-a como a velocidade da vibração que gera o som. Assim, quanto maior a velocidade de vibração mais aguda será a nota. Ambos os autores associam a propriedade de duração do som com os elementos de notação musical clave e posição da nota no pentagrama. A tonalidade tem relação com a escala de notas que é utilizada como base para a construção da música e recebe o mesmo nome da escala de notas (Lacerda, 1967). As escalas podem ser identificadas pelos símbolos de sustenido (\#) ou bemol (b) apresentados no início da partitura (Med, 1996).

Por fim, a propriedade sonora de timbre é determinada pela qualidade do som e é responsável por permitir reconhecer a origem do som (Lacerda, 1967). Med (1996, p. 12) caracteriza a mesma propriedade sonora como a "combinação de vibrações determinadas pela espécie do agente que as produz". Ambos autores associam a propriedade de timbre do som com o elemento de notação musical de indicação da voz ou instrumento que deve executar a música. 
IX Congresso Brasileiro de Informática na Educação (CBIE 2020)

Anais do XXVI Workshop de Informática na Escola (WIE 2020)

\section{MÉTODO}

O método para produção e avaliação do Tagarela em sua versão de musicoterapia seguiu as etapas abaixo:

a) estudo: nessa etapa foram aprofundados os conceitos de musicoterapia, música, arquivos Musical Instrument Digital Interface (MIDI) e o framework Ionic, no qual a aplicação foi desenvolvida;

b) especificação: nessa etapa foi realizada a definição de requisitos que o aplicativo deveria atender, bem como o detalhamento da estrutura de análise e projeto do mesmo;

c) implementação: essa etapa consistiu em escrever computacionalmente os códigos relativos ao aplicativo especificado;

d) testes: nessa etapa foram feitos testes para garantir o adequado funcionamento de todas as rotinas implementadas de acordo com a especificação, bem como foram realizadas entrevistas com dois especialistas e aplicação com um aluno autista, a qual foi analisada por meio de observação em conjunto com um profissional musicoterapeuta;

e) análise: nessa etapa foram avaliados os resultados obtidos com a aplicação do software e as impressões dos profissionais e do estudante.

\section{DESCRIÇÃO DO APLICATIVO}

O aplicativo disponibiliza para o usuário uma forma de combinar fragmentos musicais para gerar uma composição musical personalizada. O processo de criação da composição musical personalizada é organizado em etapas. Em cada etapa o usuário deve escolher um fragmento musical dentre os possíveis fragmentos exibidos pelo aplicativo. Quando um fragmento é escolhido, ele é adicionado à composição. Os fragmentos não escolhidos são descartados e uma nova etapa de escolha se inicia. Para estruturar os dados dos fragmentos musicais e organizar a dinâmica de composição musical o aplicativo utiliza quatro elementos:

a) opção: é o elemento que representa um fragmento musical;

b) linha: é o elemento que agrupa as opções;

c) passo: é o elemento que agrupa linhas;

d) fonte de composição: é o elemento que agrupa passos.

Cada um deles, com exceção da opção, representa uma pasta no diretório do aplicativo no dispositivo móvel. Já a opção representa um arquivo MIDI. A relação entre os elementos ocorre pela localização das pastas e arquivos. Essa característica possibilita que novos arquivos e pastas sejam criados e submetidos ao aplicativo. Com isso o profissional que utiliza o aplicativo pode personalizar a atividade de composição. A Figura 2 exibe o fluxograma que representa o processo de criação de composição musical.

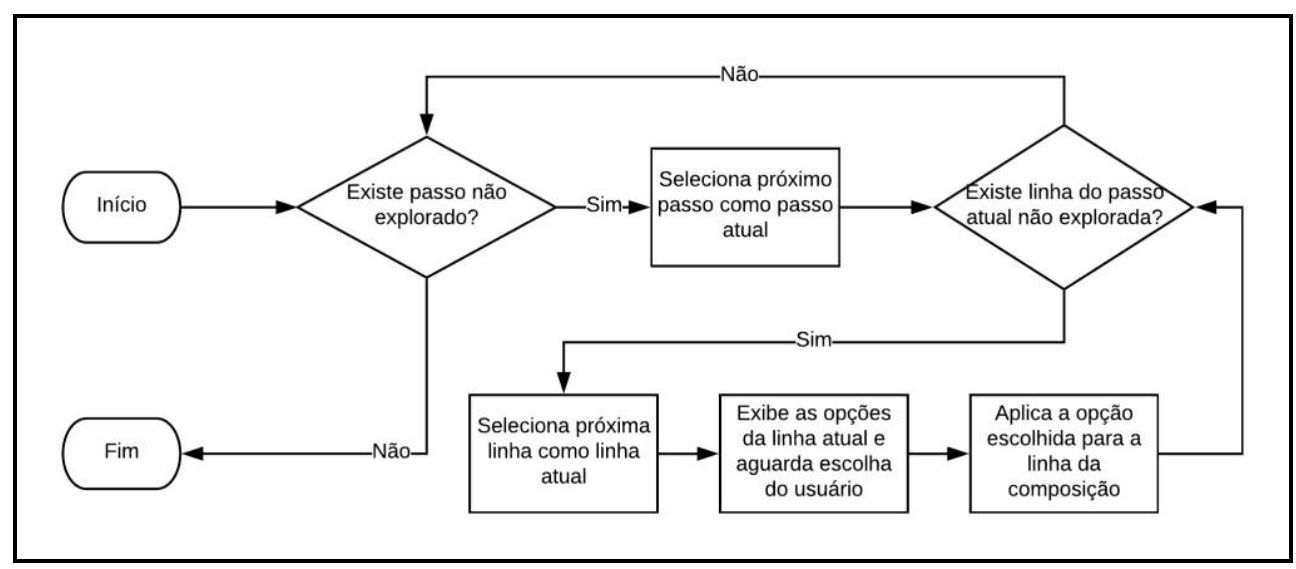

Fonte: elaborado pelos autores.

Figura 2 - Processo de criação de composição musical 
Quando o aplicativo é iniciado a primeira ação solicitada para o usuário é a escolha de uma fonte de composição. Assim que a escolha é realizada o aplicativo carrega para a memória os arquivos MIDI da composição escolhida e os classifica em cada passo e linha em razão da organização dos arquivos e pastas. Também é nesta etapa que os dados de configuração anteriormente salvos são recarregados, caso existam.

Uma vez que os dados foram carregados pelo processo de carga de dados, a etapa de parametrização do processo de composição se inicia. Nesta etapa, o usuário pode determinar valores para parâmetros de opções, linhas, passos ou fonte de composição. Esses parâmetros serão utilizados durante o processo de composição para determinar quais valores o usuário pode aplicar às propriedades sonoras da composição. Os parâmetros também podem determinar o tamanho mínimo das opções em cada passo ou determinar se dados serão exibidos ou não durante o processo de composição. O usuário que realiza essa configuração é o musicoterapeuta. A Figura 3 apresenta os quatro grupos de configuração da composição musical que o aplicativo disponibiliza. Alguns dos elementos que podem ser configurados nessa etapa são:

a) valores mínimo, máximo e inicial de andamento;

b) tonalidades disponíveis e tonalidade inicial;

c) valores mínimo, máximo e inicial de volume;

d) instrumentos musicais disponíveis para escolha.

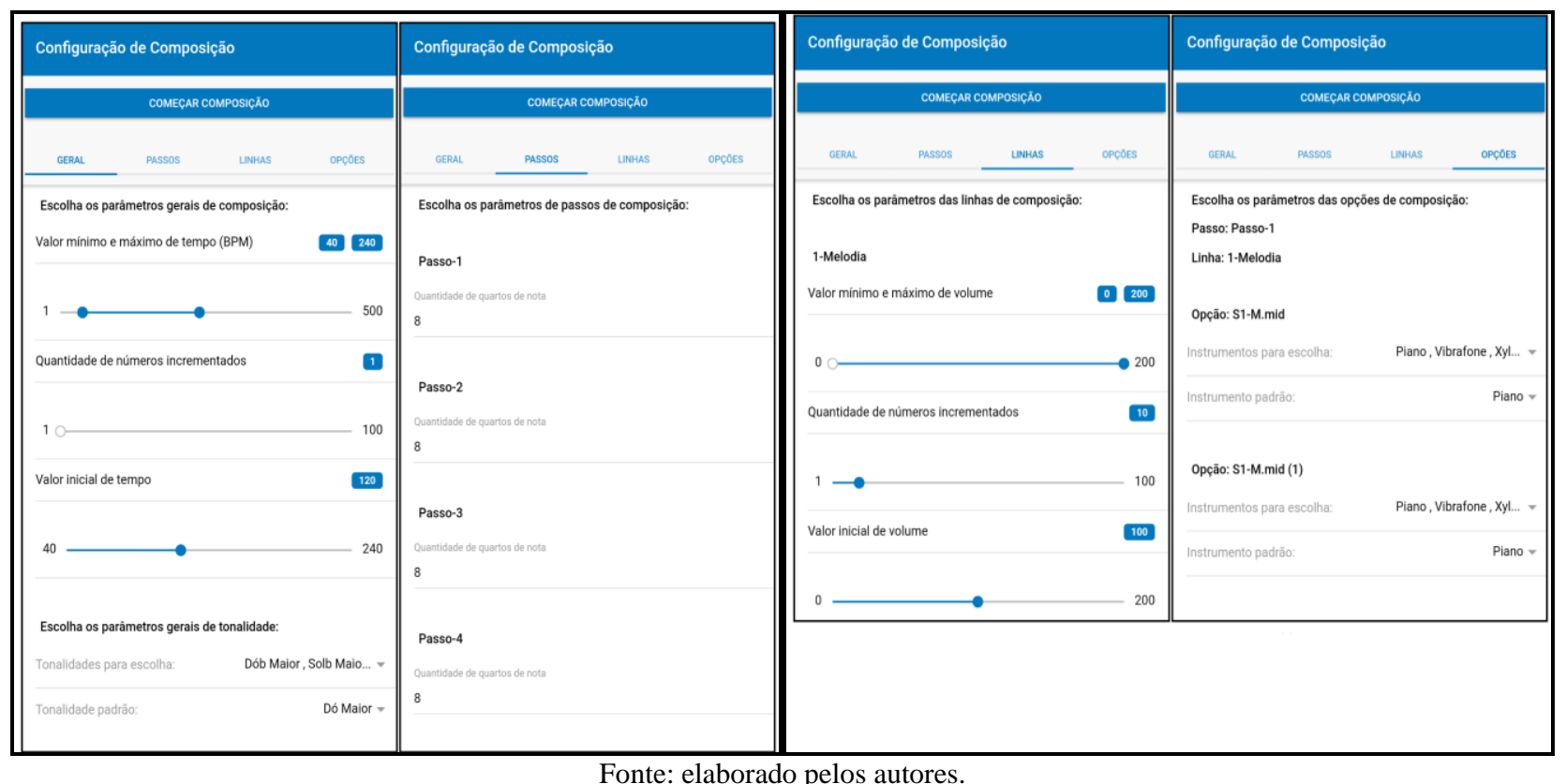

Figura 3 - Tela de configuração do aplicativo

O processo de parametrização da composição se encerra quando o botão começar composição é pressionado. Nesse momento o arquivo de configuração é persistido, de acordo com o tipo da fonte de composição. Uma vez que o processo de configuração é concluído, a tela de composição musical é exibida. Neste ponto as classes de controle e modelo de composição já estão instanciadas e com os dados carregados para que o processo de composição se inicie. Nesta etapa, o usuário interage com a representação dos elementos de composição existentes na tela do aplicativo para montar sua composição musical personalizada e editar as propriedades sonoras dos elementos em questão. A Figura 4 apresenta a tela de composição do aplicativo com seus componentes identificados por números. O usuário que opera essa tela é o indivíduo que está em terapia.

A tela de composição pode ser dividida em quatro partes: item 1: barra de controle geral da composição; item 2: card que exibe os dados de composição; item 3: card que exibe as opções de configuração; item 4: card que apresenta as opções escolhidas pelo usuário alocadas nas linhas e 
posições correspondentes à escolha. Por questões de ordenação e sequência do processo de composição, os itens serão apresentados na sequência: $3,4,1$ e 2 .

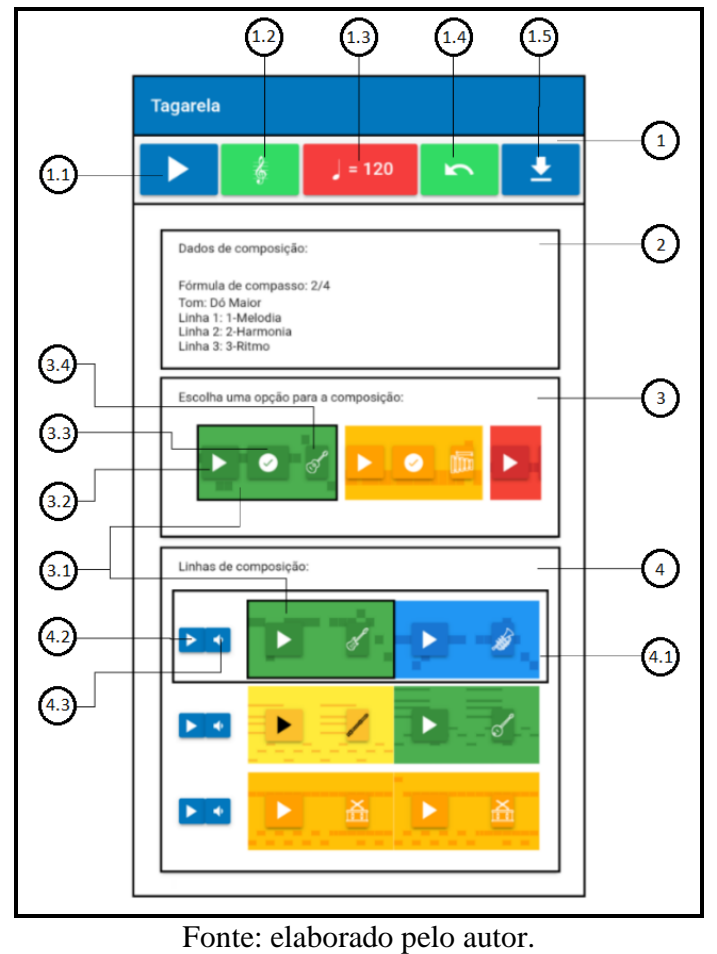

Figura 4 - Tela de composição musical do aplicativo

No item 3, cada representação de opção de configuração contém três botões representados por: item 3.2, item 3.3 e item 3.4. O item 3.2 é o botão que inicia a reprodução do objeto MIDI. O item 3.3 é o botão que realiza a escolha do fragmento musical como parte da composição musical. A inserção de fragmentos faz com que o item 3 atualize sua lista de opções disponíveis. O item 3.4 é o botão que altera o instrumento musical que está associado com a opção. Neste caso, a lista de valores a ser exibida é a lista de instrumentos musicais definidos na fase de configuração da composição para a opção. A cada instrumento está associada uma cor. Assim, o item 3.1 apresenta a cor do instrumento musical escolhido como tema para os botões.

O item 4 é o card que representa as linhas da composição musical. Para cada linha, um item 4.1 é criado. Além da representação das opções que compõem a linha, no início dos itens 4.1, existem dois botões. Estes botões, item 4.2 e item 4.3, representam as opções de execução da linha e alteração do volume da linha respectivamente. Quando item 4.2 é acionado, o processo de execução de todas as opções que compõem a linha se inicia. Quando isto ocorre, o processo de execução do áudio é o mesmo que ocorre no item 3.2. Porém é necessário criar um novo arquivo MIDI e concatenar os espectros de todas as opções envolvidas para representar a linha em questão.

$\mathrm{O}$ item 1 contém as opções que aplicam ações gerais à composição. O item 1.1 realiza a execução da composição pelo mesmo componente que realiza a execução da opção ou da linha. $\mathrm{O}$ item 1.2 é o botão responsável por realizar a alteração da tonalidade da composição. O item 1.3 é responsável por realizar a alteração de andamento da composição. O item 1.4 é responsável por desfazer a última escolha do usuário. Com estas alterações, os elementos da tela de composição são atualizados. O último botão, o item 1.5, é o botão que realiza o download da composição.

Finalmente, o item 2 é o card responsável por apresentar ao usuário dados sobre a composição. Este card é exibido, ou não, de acordo com a escolha realizada na fase de configuração. Os dados exibidos são referentes às propriedades globais da composição ou dados 
IX Congresso Brasileiro de Informática na Educação (CBIE 2020)

Anais do XXVI Workshop de Informática na Escola (WIE 2020)

atuais sobre as etapas de composição. Os dados exibidos são: fórmula de compasso, tom, linha atual, quantidade de linhas, passo atual, quantidade de passos e nome das linhas.

\section{RESULTADOS}

Foram realizados três tipos de testes com o aplicativo: das principais funcionalidades, com profissionais da área de música e em atividade terapêutica.

\subsection{Testes de funcionalidades}

Para validar as funcionalidades do aplicativo, além de testes realizados na plataforma Android, foram realizados testes na plataforma iOS. $\mathrm{Na}$ plataforma Android todas as funcionalidades se comportaram conforme o esperado. Executando o aplicativo em um dispositivo iOS, foi identificado que quase todas as funcionalidades se comportam de forma igual ao dispositivo Android. A única funcionalidade que apresentou problemas foi a execução de arquivos MIDI com o plugin Media do Ionic. Quando algum botão de execução de arquivo MIDI do aplicativo é acionado na plataforma iOS um erro do componente AVAudioPlayer. Ao verificar o código fonte do plugin Media na versão 5.0.2, que é a utilizada no aplicativo, nenhuma referência ao componente AVMIDIPlayer, que realiza a execução de arquivos MIDI na plataforma iOS, é encontrada. Portanto, o aplicativo, apesar se ser executado, não está funcional na plataforma iOS.

Para realizar testes de carga de dados do aplicativo foram criados os arquivos MIDI das quatro fontes de composição disponibilizadas juntamente com a instalação do aplicativo. Para tanto, foi utilizado um software editor de partituras para criar todas as opções em questão. O software editor de partituras utilizado possibilita a exportação de partituras em arquivos MIDI. O primeiro teste realizado foi criar uma partitura para cada opção da fonte de composição e realizar a extração da partitura em formato de arquivo MIDI de cada opção. Quando estas opções foram disponibilizadas para o aplicativo, a composição criada apresentou assincronia entre as opções. Algumas opções começaram a ser executadas frações de segundo antes ou depois que outras opções do mesmo passo. Para corrigir esta questão foi necessário criar uma partitura para cada passo da fonte de composição. Após a extração do arquivo MIDI que representa o passo, foi necessário replicá-lo criando uma cópia para cada linha. Cada arquivo desses foi editado com um editor de arquivos binários para remover as opções que não faziam parte da linha que o arquivo representa. Com esta tratativa, a execução de todas as opções sincronizou dentro do mesmo passo.

Sendo assim, a estrutura criada para disponibilizar as opções ao aplicativo funciona. Porém, foi necessária a edição dos arquivos gerados pela ferramenta utilizada para criar os fragmentos musicais. Esta questão demonstra que a qualidade da fonte de composição é dependente da ferramenta utilizada para criar as opções. Caso a ferramenta não garanta a consistência entre as opções, a composição gerada na utilização do aplicativo poderá não ser coerente com regras de teoria musical.

\subsection{Testes de utilização por profissionais}

Para validar os aspectos de utilização do aplicativo e verificar a possibilidade de utilização dele como ferramenta durante um processo de terapia, foram realizadas duas entrevistas com dois profissionais. O Entrevistado 1 é professor de música na Educação Superior e o Entrevistado 2 atua com aulas de música e atividades terapêuticas para autistas envolvendo música. As entrevistas tiveram como propósito apresentar a dinâmica de composição proporcionada pelo aplicativo, explorar todas as funcionalidades do processo de composição e do processo de configuração e obter sugestões de melhoria e viabilidade de utilização do aplicativo. Para ambas as entrevistas foi utilizado o mesmo roteiro de apresentação do aplicativo.

Com o Entrevistado 1 todas as funcionalidades dispostas em tela funcionaram conforme o esperado. As ações de todos os botões foram entendidas sem a necessidade de explicações 
recorrentes. Porém, a dinâmica de composição não ficou clara somente com a explicação inicial. Foi necessário realizar as escolhas de opções para todas as linhas do primeiro passo para que o entendimento total da atividade ocorresse. Quando o processo de composição do segundo passo foi iniciado, a dinâmica foi entendida e daí em diante não surgiram mais dúvidas em relação ao processo de composição. Nos testes de configuração houve somente um questionamento de funcionalidade. Todos os atributos editados durante a fase de configuração funcionaram conforme $o$ esperado. O questionamento que ocorreu foi em relação aos parâmetros de passo, que realizam a adequação do tamanho dos fragmentos musicais uma vez que esta funcionalidade não está disponível. Neste caso, o próprio aplicativo realiza ajustes de acordo com a análise de todos os fragmentos existentes em um passo. Foi explicado que, devido a não ser possível garantir que os fragmentos musicais possuam sempre todos os dados necessários para o fim de um fragmento musical, esta opção foi mantida como um parâmetro de configuração.

A validação com o Entrevistado 2 obteve resultados similares. Uma diferença entre as duas entrevistas foi o dispositivo utilizado para a demonstração. Enquanto com o Entrevistado 1 foi utilizado um tablet, para o Entrevistado 2 foi disponibilizado um celular. Devido ao tamanho reduzido dos elementos em tela, ele sentiu dificuldade para realizar algumas ações com botões muito próximos. A dinâmica de composição não foi completamente entendida somente com a primeira explicação. Foi necessário, assim como na primeira entrevista, realizar todas as escolhas do primeiro passo para que o processo fizesse sentido para o usuário. Após isso, nenhuma dificuldade foi enfrentada. Quando questionado sobre a possibilidade de utilização do aplicativo em algum processo de terapia, a resposta do Entrevistado 2 foi positiva. Segundo ele, é necessário que o aplicativo consiga prender a atenção do usuário, sendo que as cores utilizadas e a representação dos arquivos MIDI em espectros coloridos ajudaram nessa tarefa. Devido às questões de usabilidade do aplicativo, o entrevistado ressaltou que é necessário que o usuário possua idade suficiente para entender os conceitos envolvidos na dinâmica de composição. A única sugestão de melhoria para o aplicativo realizada pelo entrevistado foi utilizar trechos de músicas conhecidas dos alunos como fonte de composição.

\subsection{Testes de utilização em atividade terapêutica}

Para verificar como o aplicativo funciona em uma atividade de terapia musical, foi realizado um teste com um aluno do Entrevistado 2, acompanhado por ele. O aluno que participou do teste, com 18 anos de idade, era autista. Durante a aula de música, o Entrevistado 2 fez utilização do aplicativo explicando ao aluno que ele iria criar uma música. O processo de composição se iniciou com o professor executando cada opção que o aluno poderia escolher para o primeiro passo e primeira linha. Após, o professor solicitou para o aluno que ele escolhesse uma das opções executadas. Uma vez que todas as escolhas do passo foram finalizadas, o professor realizou a execução da composição completa. Esse processo se repetiu até a finalização da composição. A primeira composição foi realizada com o professor guiando o aluno em todas as ações. Foram realizadas mais três composições além da primeira. Nestas, o aluno foi ganhando autonomia até chegar ao ponto de realizar uma composição praticamente sozinho. Isto demonstra que, conforme afirmado pelo professor, o aplicativo foi capaz de prender a atenção do aluno.

Após a atividade, o Entrevistado 2 afirmou que o resultado para o aluno em questão foi positivo. $\mathrm{O}$ aluno conseguiu realizar a composição e se manteve entretido durante o processo. Mesmo sem conhecimento teórico musical aprofundado, ele foi capaz de criar composições musicais com o auxílio do aplicativo. Apesar deste resultado, o entrevistado alerta que o aluno que participou do teste é muito musical e possui um grau leve de autismo. Pode ser que esse resultado não seja o mesmo em outros casos. Um dos motivos para isto, destacado por ele, é a variação de interesse que a música desperta em cada aluno. O grau de autismo, para os casos tratados também irá impactar nesse resultado. Novamente a utilização de fragmentos musicais conhecidos como fonte de composição foi abordada pelo Entrevistado 2. Segundo ele, os alunos se apegam a 
IX Congresso Brasileiro de Informática na Educação (CBIE 2020)

Anais do XXVI Workshop de Informática na Escola (WIE 2020)

melodias já conhecidas. Este fator pode colaborar para que o aluno se mantenha interessado no processo de composição.

\section{CONCLUSÕES}

O aplicativo provou ser capaz de auxiliar o musicoterapeuta em atividades de composição musical. No teste realizado com um aluno autista, os requisitos destacados pelo Entrevistado 2 para a utilização da ferramenta foram atingidos. O aluno autista conseguiu entender a dinâmica de composição e o aplicativo conseguiu prender a sua atenção. Mesmo sem possuir conhecimento teórico musical, o autista foi capaz de utilizar o aplicativo para construir uma composição musical. De qualquer forma, como destacado pelo Entrevistado 2, o resultado apresentado durante o teste pode não se repetir com outros alunos. Este pode variar de acordo com o nível de interesse que a música desperta no aluno e a natureza de sua necessidade. Mesmo assim, o teste mostrou-se promissor para que o aplicativo possa contribuir socialmente ampliando a gama de ferramentas tecnológicas que podem ser utilizadas em musicoterapia. Este fator está associado com um aspecto de inclusão, uma vez que o aplicativo possibilita que pessoas com necessidades especiais possam efetuar atividades musicais de composição utilizando um dispositivo móvel.

Apesar de se mostrar utilizável em um ambiente de terapia musical, o aplicativo possui algumas limitações que podem ampliar sua utilização caso resolvidas. $\mathrm{O}$ fator de personalização da fonte de composição que o aplicativo proporciona funciona. Tanto no aspecto de configuração da atividade de composição musical, quanto na possibilidade de criação de fontes de composição personalizadas. Porém, os fragmentos musicais utilizados nas fontes de composição devem ser consistentes entre si para que a composição criada pelo usuário também seja. Este fato pode dificultar a utilização personalizada do aplicativo, pois a ferramenta utilizada para gerar os fragmentos musicais pode não manter a consistência necessária. Outro fator de limitação apresentado nos testes foi a impossibilidade da execução na plataforma iOS. Isto limita a quantidade de usuários que podem utilizar o aplicativo. Por fim, conforme demonstrado nos testes realizados com profissionais, o modo como os elementos musicais são representados em tela não é sugestivo, apesar da atividade funcionar após o entendimento da dinâmica de composição.

As possíveis extensões mapeadas durante os processos de desenvolvimento e teste do aplicativo são: desenvolver um novo plugin de execução de arquivos MIDI para Ionic, possibilitando a execução do aplicativo em dispositivos iOS; adicionar a possibilidade de edição de fragmentos musicais personalizados para torná-los consistentes entre si; reformular a forma com que os elementos musicais são exibidos em tela para que o aplicativo seja mais sugestivo; refinar o processo de composição para permitir variações de velocidade e tonalidade ao decorrer da composição; criar fontes de composição com músicas conhecidas; realizar mais testes do aplicativo com uma quantidade maior de alunos para identificar mais possibilidades de melhorias e ampliar a quantidade de pessoas que conseguem utilizar o aplicativo.

\section{AGRADECIMENTOS}

Agradecemos à Fundação de Apoio à Pesquisa e Inovação do Estado de Santa Catarina (FAPESC) pelo financiamento ao Laboratório Interdisciplinar de Formação de Educadores (LIFE) da Universidade Regional de Blumenau (FURB) e à FURB pelas condições oferecidas para a realização deste trabalho.

\section{REFERENCIAS:}

BARBOSA, Jaiane; DOURADO, Tereza. Tecnologias Móveis: Laptop XO e suas Contribuições para o Ensino de Música na Escola. Anais dos Workshops do Congresso Brasileiro de Informática na Educação, [S.1.], p. 866, nov. 2016. ISSN 2316-8889. 
IX Congresso Brasileiro de Informática na Educação (CBIE 2020)

Anais do XXVI Workshop de Informática na Escola (WIE 2020)

BARCELLOS, Lia Rejane Mendes. Musicoterapia: alguns escritos. Rio de Janeiro: Enelivros, 2004.

BORDINI, Rogério Augusto et al. Musikinésia: Jogo Eletrônico gratuito para a Aprendizagem de Teclado e Leitura Musical. Anais dos Workshops do Congresso Brasileiro de Informática na Educação, [S.1.], p. 225, nov. 2016.

BRUSCIA, Kenneth, E. Definindo musicoterapia. 3. ed. Dallas: Barcelona Publishers, 2016.

CAZAGRANDA, Lucas. 2016. Aprendendo Braille: o ensino do sistema Braille com o uso do Tagarela. 2016. 58 f. Trabalho de Conclusão de Curso (Bacharelado em Ciência da Computação). Centro de Ciências Exatas e Naturais, Universidade Regional de Blumenau, Blumenau.

FABENI, Alan Filipe Cardozo. Tagarela: aplicativo para comunicação alternativa no IOS. 2012. 106 f. Trabalho de Conclusão de Curso (Bacharelado em Ciência da Computação). Universidade Regional de Blumenau, Blumenau.

FERREIRA, André Felipe. Tagarela: módulo jogo de letras e número. 2016. 55 f. Trabalho de Conclusão de Curso (Bacharelado em Ciência da Computação). Centro de Ciências Exatas e Naturais, Universidade Regional de Blumenau, Blumenau.

LACERDA, Osvaldo. Compendio de teoria elementar da música. 3.ed. São Paulo: Ricordi Brasileira, 1967.

MED, Bohumil. Teoria da música. 4. ed. Brasília: Musimed, 1996.

MILETTO, Evandro M. et al. Grupo de Pesquisa Informática Aplicada IFRS - Campus Porto Alegre. Anais dos Workshops do Congresso Brasileiro de Informática na Educação, [S.1.], p. 182, jan. 2015.

MOURA, Edson. Tocando e cantando poesia: uma aprendizagem multidisciplinar e cooperativa em arte. Anais dos Workshops do Congresso Brasileiro de Informática na Educação, [S.l.], nov. 2012

PINHATI, Fernando; SIQUEIRA, Sean W. M.. Plataforma Mignone: Uma Arquitetura para Ambientes Virtuais e um Modelo para Construção de Objetos de Aprendizagem Especializados para Educação Musical. Anais dos Workshops do Congresso Brasileiro de Informática na Educação, [S.1.], nov. 2013.

PRIOLLI, Maria Luisa de Mattos. Princípios básicos da música para a juventude. 48. ed. Rio de Janeiro: Casa Oliveira de Músicas LTDA., 2006.

QUEIROZ, Gregorio Jose Pereira De. A música compõe o homem, o homem compõe a música. São Paulo: Editora Cultrix, 2000.

SAUTNER, Guilherme. Tagarela: módulo de desenvolvimento e aquisição de linguagem para crianças autistas. 2017. 55 f. Trabalho de Conclusão de Curso (Bacharelado em Ciência da Computação). Centro de Ciências Exatas e Naturais, Universidade Regional de Blumenau, Blumenau.

VERA, William Fabian Machado et al. Dó, Ré, Mergesort: um relato de experiência interdisciplinar de ensino de computação com matemática e música. Anais dos Workshops do Congresso Brasileiro de Informática na Educação, [S.1.], p. 1275, nov. 2016.

WATANABE, Marli Kiyoko Fujikawa; TSUKIMOTO, Denise Rodrigues; TSUKIMOTO, Gracinda Rodrigues. Terapia ocupacional e o uso do computador como recurso terapêutico. Acta Fisiátrica, São Paulo, v. 10, n. 1, p. 17-20, 2003. 